\title{
Modelling the impact of larviciding on the population dynamics and biting rates of Simulium damnosum (s.l.): implications for vector control as a complementary strategy for onchocerciasis elimination in Africa
}

Isobel Routledge ${ }^{1}$, Martin Walker ${ }^{2,3}$, Robert A. Cheke ${ }^{3,4}$, Samir Bhatt ${ }^{1}$, Pierre Baleguel Nkot ${ }^{5}$, Graham A. Matthews ${ }^{6}$, Didier Baleguel ${ }^{5}$, Hans M. Dobson ${ }^{4}$, Terry L. Wiles ${ }^{5,6}$ and Maria-Gloria Basañez ${ }^{1,3^{*}}$ (D)

\begin{abstract}
Background: In 2012, the World Health Organization set goals for the elimination of onchocerciasis transmission by 2020 in selected African countries. Epidemiological data and mathematical modelling have indicated that elimination may not be achieved with annual ivermectin distribution in all endemic foci. Complementary and alternative treatment strategies (ATS), including vector control, will be necessary. Implementation of vector control will require that the ecology and population dynamics of Simulium damnosum (sensu lato) be carefully considered.

Methods: We adapted our previous SIMuliid POPulation dynamics (SIMPOP) model to explore the impact of larvicidal insecticides on S. damnosum (s.l.) biting rates in different ecological contexts and to identify how frequently and for how long vector control should be continued to sustain substantive reductions in vector biting. SIMPOP was fitted to data from large-scale aerial larviciding trials in savannah sites (Ghana) and small-scale ground larviciding trials in forest areas (Cameroon). The model was validated against independent data from Burkina Faso/Côte d'Ivoire (savannah) and Bioko (forest). Scenario analysis explored the effects of ecological and programmatic factors such as pre-control daily biting rate (DBR) and larviciding scheme design on reductions and resurgences in biting rates.

Results: The estimated efficacy of large-scale aerial larviciding in the savannah was greater than that of ground-based larviciding in the forest. Small changes in larvicidal efficacy can have large impacts on intervention success. At 93\% larvicidal efficacy (a realistic value based on field trials), 10 consecutive weekly larvicidal treatments would reduce DBRs by $96 \%$ (e.g. from 400 to 16 bites/person/day). At 70\% efficacy, and for 10 weekly applications, the DBR would decrease by $67 \%$ (e.g. from 400 to 132 bites/person/day). Larviciding is more likely to succeed in areas with lower water temperatures and where blackfly species have longer gonotrophic cycles.

(Continued on next page)
\end{abstract}

\footnotetext{
* Correspondence: m.basanez@imperial.ac.uk

${ }^{1}$ MRC Centre for Outbreak Analysis and Modelling, Department of Infectious

Disease Epidemiology, School of Public Health, Faculty of Medicine (St Mary's campus), Imperial College London, Norfolk Place, London W2 1PG, UK

${ }^{3}$ London Centre for Neglected Tropical Disease Research (LCNTDR),

Department of Infectious Disease Epidemiology, School of Public Health,

Faculty of Medicine (St Mary's campus), Imperial College London, Norfolk

Place, London W2 1PG, UK

Full list of author information is available at the end of the article
}

(c) The Author(s). 2018 Open Access This article is distributed under the terms of the Creative Commons Attribution 4.0 International License (http://creativecommons.org/licenses/by/4.0/), which permits unrestricted use, distribution, and reproduction in any medium, provided you give appropriate credit to the original author(s) and the source, provide a link to the Creative Commons license, and indicate if changes were made. The Creative Commons Public Domain Dedication waiver (http://creativecommons.org/publicdomain/zero/1.0/) applies to the data made available in this article, unless otherwise stated. 
(Continued from previous page)

Conclusions: Focal vector control can reduce vector biting rates in settings where a high larvicidal efficacy can be achieved and an appropriate duration and frequency of larviciding can be ensured. Future work linking SIMPOP with onchocerciasis transmission models will permit evaluation of the impact of combined anti-vectorial and anti-parasitic interventions on accelerating elimination of the disease.

Keywords: Onchocerciasis, Vector control, Vector ecology, Mathematical modelling, Population dynamics, Alternative treatment strategy, Elimination, Simulium damnosum (s.I.), Africa

\section{Background}

Human onchocerciasis, also known as river blindness, is a neglected tropical disease (NTD) $[1,2]$ caused by the filarial parasitic nematode, Onchocerca volvulus. The parasite spreads through the bite of blackflies within the genus Simulium, which act as disease vectors. Onchocerciasis has posed a serious public health and socioeconomic burden for many countries in sub-Saharan Africa (SSA), and foci in Latin America and Yemen [3]. The disease continues to have devastating effects on the quality of life of those infected, over $99 \%$ of whom live in SSA [4].

Fortunately, great strides have been made in onchocerciasis control over the past 60 years. The Onchocerciasis Control Programme in West Africa (OCP, 1974-2002), initially an anti-vectorial intervention in 11 countries, averted 600,000 cases of preventable blindness and made 25 million hectares of land habitable and productive [5]. The African Programme for Onchocerciasis Control (APOC, 1995-2015), mainly an anti-parasitic intervention in the remaining endemic African countries, averted an estimated 17.4 million disability-adjusted life years (DALYs) [6]. Onchocerciasis control has been praised as one of the most cost-effective interventions of the last 100 years, both from the perspectives of public health [7] and economic development [8,9]. Mass drug administration (MDA) through community-directed treatment with ivermectin (CDTI) has saved an estimated 500,000 DALYs every year at US\$7 per DALY $[6,10]$. None of these programmes, however, led to regional elimination of $O$. volvulus by the time of their closure.

Current World Health Organization (WHO) targets are to eliminate the disease in selected African countries by 2020 , and in at least $80 \%$ of onchocerciasis endemic African countries by 2025 [11, 12]. As the focus shifts towards elimination, there is a need to consider whether the current control strategy (mainly annual CDTI) is satisfactory to achieve elimination in all epidemiological contexts. Evidence suggests that complementary and/or alternative treatment strategies (ATS) [13] should be considered for foci with high pre-control transmission intensity (hyper- and holoendemic areas with baseline microfilarial prevalence in excess of 60\%) [14, 15], where sub-optimal responses to ivermectin have been documented [16, 17], and where co-endemicity with Loa loa (African eye-worm) - particularly in the case of hypoendemic onchocerciasis - contraindicates ivermectin MDA due to the risk of severe adverse events (SAEs) when treating individuals with very high $L$. loa microfilaraemia [18, 19].

Localized vector control through ground-based larviciding has been recommended as one of the ATS to be carried out in combination with CDTI, or with test-andtreat/not-treat strategies where co-endemicity with $L$. loa is a concern $[13,20]$. However, many questions remain as to where, when, how frequently, for how long and how focal vector control should be implemented. For instance, Uganda is the only country in SSA whose onchocerciasis elimination programme currently combines vector control and ivermectin treatment [21], yet the Ugandan experience may not be directly applicable to other African settings given the very specific ecological requirements of the local $S$. neavei vector (whose immature stages have a phoretic association with freshwater crabs). However, S. damnosum (sensu lato) is also important in Uganda.

It is, therefore, essential to understand vector ecology and population dynamics when deciding where, when and how to implement larviciding programmes in focal areas. Members of the S. damnosum (s.l.) complex, which transmit $O$. volvulus in most of Africa, are sub-categorised into numerous cytospecies, which have differing vector competences, vectorial capacities and could have different susceptibilities to insecticides. Therefore, cytospecies identities are important to consider when designing vector control strategies. A separation on ecological and epidemiological grounds is often made between cytospecies which reside in savannah habitats, such as $S$. damnosum (sensu stricto) and S. sirbanum, and those in forested areas, such as S. sanctipauli and S. yahense.

However, onchocerciasis transmission dynamics and control models such as EPIONCHO and ONCHOSIM do not currently consider details of the population dynamics of the vectors, but tend to use only a simulated reduction in vector biting rates when modelling vector control, rather than modelling explicitly the effect on the vector population of killing the simuliid larvae [22]. This could lead to misleading results when considering 
the epidemiological impact of focal vector control strategies because Simulium population dynamics and vector ecology have important effects on the implementation and outcomes of several aspects of vector control including optimal timing (regarding vector and parasite), frequency and duration, in addition to potential nonlinear effects due to the density-dependent processes that regulate vector and parasite abundance.

In this paper we use our previously developed SIMuliid POPulation dynamics (SIMPOP) model [23] to investigate under which contexts focal vector control would be successful in reducing adult vector biting rates substantially and to identify how frequently and for how long vector control would need to be carried out to effect substantive reductions in blackfly vector biting.

\section{Methods}

\section{Data sources}

\section{OCP savannah site: Asubende, Ghana}

This dataset, from an onchocerciasis hyperendemic savannah region located in the eastern part of the southern extension of OCP on the Pru river in Ghana, comprises daily biting rates (DBRs, the number of bites per person per day) from human landing catches recorded between August 1987 and March 1988. Larviciding started in the area in January 1986 but was interrupted in June 1987 and resumed on 10 February 1988 due to ongoing trials of the impact of ivermectin MDA on transmission [24]. Here S. damnosum (s.s.) is the dominant vector but $S$. sirbanum is also found. This dataset was used to fit the model and estimate parameters pertaining to savannah settings as listed in Table 1.

\section{OCP pilot studies at savannah sites: Burkina Faso/Côte d'Ivoire}

This dataset [25] contains weekly averages of DBRs recorded at three savannah sites (Léraba Bridge, Chaussée Niakaramandougou and Naniénavogo) in Burkina Faso/ Côte d'Ivoire during 1975 in the south-western section of the original OCP control area, where aerial larviciding was introduced. These data came from early pilot field trials where vector control had not previously been carried out and were measured by landing catches on human attractants. This dataset was used for model validation purposes regarding savannah settings.

\section{Focal vector control in forested sites: Sanaga Valley, Cameroon}

In 2005, the Yaoundé Initiative Foundation (YIF) began to pilot integrated vector control which targeted vectors of both malaria and onchocerciasis in the Sanaga Valley in Cameroon [26], a forest area where the principal vector of onchocerciasis is S. squamosum B [27]. Under this integrated vector control trial, larviciding occurred for 3 applications every 10 days at two sites upstream of the Kikot falls (Lenouck and Ntol), and was carried out in a focal manner, delivered by pirogue (small boat) [26] Samples of vegetation were taken from the Kikot falls to identify the reduction in larval populations, and adult flies were caught using sticky traps (rather than human attractants), similar to those described in [28]. Since these data are not based on DBRs, a directly proportional relationship between fly density on sticky traps and DBR that had been determined by the YIF field team in their trial was used, with 50 flies/trap/day being approximately equivalent to 160 bites/person/day (i.e. DBR $\approx 3.2 \times$ daily fly density on sticky traps). These data were used for model fitting regarding forest settings (Table 1). Data also exist from antivectorial intervention in the Sanaga river, where larviciding was carried out in response to fly numbers, measured by the catches on the sticky traps. When fly numbers exceeded 30 flies/trap/ day, larviciding was resumed, when it would be applied roughly every seven days until numbers of flies caught decreased below this value. These data were not used for model fitting due to the variable interval between applications dictated by reaching the chosen target vector density.

\section{Focal vector controlled forested sites: Bioko}

This dataset, recording weekly averages of DBRs during 2001 at three different sites (Musola, Barleycorn and Sampaca), was collected as part of APOC pilot studies on the effectiveness and feasibility of localized vector control in the elimination of onchocerciasis from Bioko, an island off the coast of Cameroon and part of Equatorial Guinea. Detailed collection methods were described in [29]. Bioko is covered by large swathes of forest, and the local onchocerciasis vectors (the Bioko form of $S$. yahense [30]) have now been eliminated from the island [31] (in addition to ivermectin MDA being implemented). This dataset also includes unpublished records of water temperature and $\mathrm{pH}$ at sites during the time of sampling (R. A. Cheke, unpublished data). This dataset was used for model validation regarding forest settings.

\section{SIMuliid POPulation dynamics model (SIMPOP)}

Our previously described $S$. damnosum population dynamics model [23] was modified to consider the effect of larviciding regimes on the dynamics of the immature stages and on adult DBRs of $S$. damnosum (s.l.) female flies. SIMPOP is a compartmental, population-based deterministic model described by a system of ordinary differential equations (ODEs) representing the changes in number of simuliid eggs, larvae, pupae and adult flies with time. The developmental rates of the immature stages are water-temperature dependent. The model was refined to include a time-dependent excess larval 


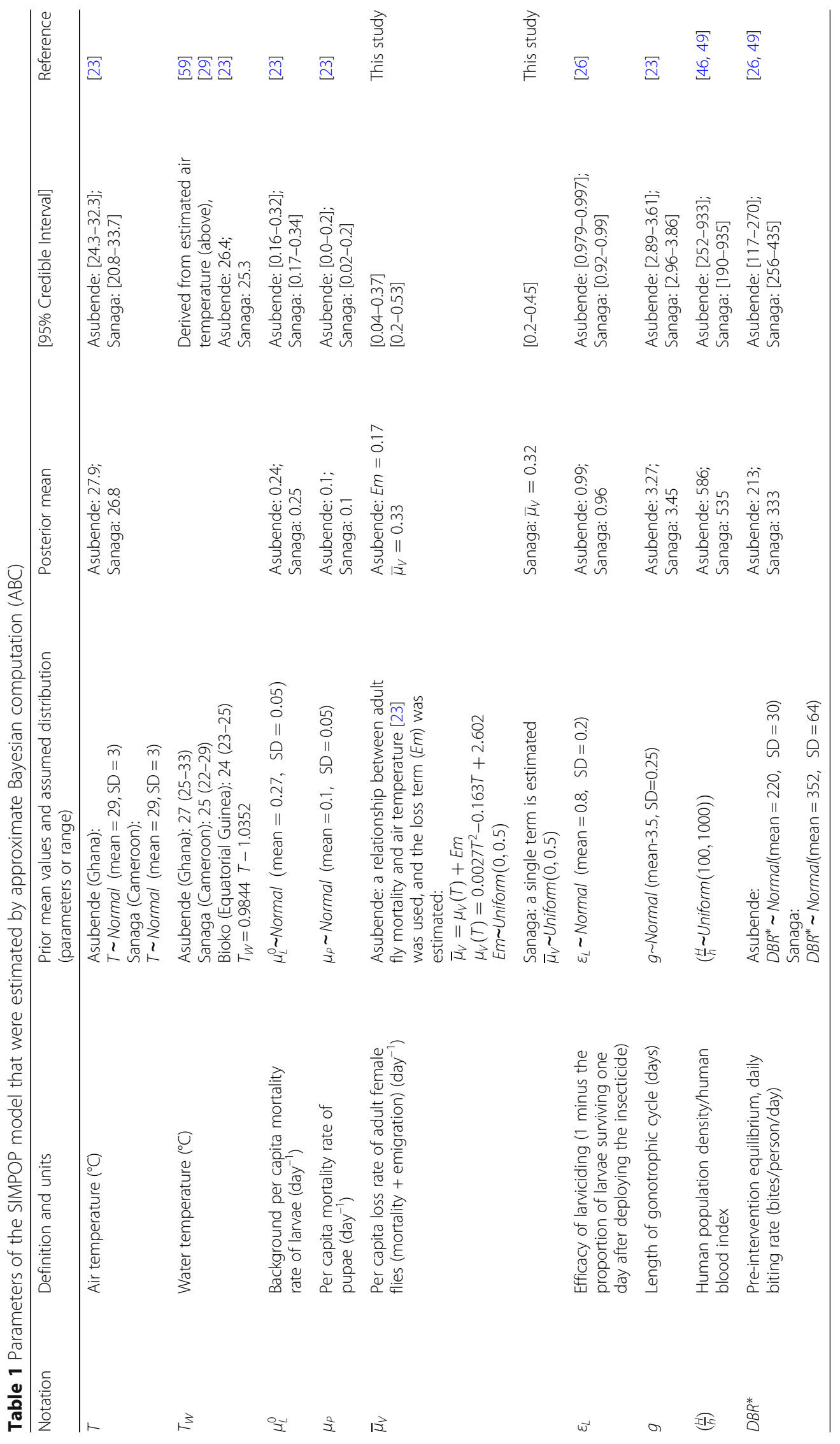


mortality term due to exposure to larviciding insecticide, a flexible "loss function" that captures both adult fly mortality and emigration, and additional larval instar stages replacing a single larval compartment to better model developmental times from larvae to pupae. (Under the assumption of a single larval compartment these would be exponentially distributed, with larvae becoming pupae very quickly; the addition of larval compartments permits a more realistic progression, with developmental times approaching a gamma distribution).

Figure 1 illustrates the flow diagram and equations (1) to (6) describe the SIMPOP model used in this study. State variables, mathematical expressions [other than equations (1)-(6)] and (fixed) model parameters are summarized in Table 2. Parameter values were either taken from [23] or, as stated above, estimated by fitting the model to data using approximate Bayesian computation (ABC) methods [32], and were informed from laboratory/field data in similar contexts (Table 1). We used the relationship between water temperature $T_{W}$ and air temperature $T$ given in [23], namely, $T_{W}=0.9844 T-1.0352$. Following [23], the rates of change with respect to time of blackfly eggs $(E)$, larvae $(L)$, pupae $(P)$ and adult (nulliparous, $N$ and parous, $\Psi$ ) female flies are given by the following
ODEs (indicating time, $t$, water temperature, $T_{W}$ and air temperatue $T$, dependencies),

$$
\begin{aligned}
\frac{d E\left(t, T_{W}\right)}{d t} & =N\left(t, T_{W}, T\right) \beta_{N} \\
& +\Psi\left(t, T_{W}, T\right) \beta_{P}-\frac{E\left(t, T_{W}\right)}{\Delta_{E}\left(T_{W}\right)} \\
& -\mu_{E}^{0}\left(1+\frac{E\left(t, T_{W}\right)}{K}\right) E\left(t, T_{W}\right),
\end{aligned}
$$

$$
\begin{gathered}
\frac{d L_{1}\left(t, T_{W}\right)}{d t}=\frac{E\left(t, T_{W}\right)}{\Delta_{E}\left(T_{W}\right)}-\left(\frac{7}{\Delta_{L}\left(T_{W}\right)}+\mu_{L}^{0}+\mu_{L}^{1}\right) L_{1}\left(t, T_{W}\right) \\
\frac{d L_{i}\left(t, T_{W}\right)}{d t}=\frac{7 L_{i-1}\left(t, T_{W}\right)}{\Delta_{L}\left(T_{W}\right)}-\left(\frac{7}{\Delta_{L}\left(T_{W}\right)}+\mu_{L}^{0}+\mu_{L}^{1}\right) L_{i}\left(t, T_{W}\right) \\
2 \leq i \leq 7,
\end{gathered}
$$

$$
\frac{d P\left(t, T_{W}\right)}{d t}=\frac{7 L_{7}\left(t, T_{W}\right)}{\Delta_{L}\left(T_{W}\right)}-\frac{P\left(t, T_{W}\right)}{\Delta_{P}\left(T_{W}\right)}-P\left(t, T_{W}\right) \mu_{P},
$$

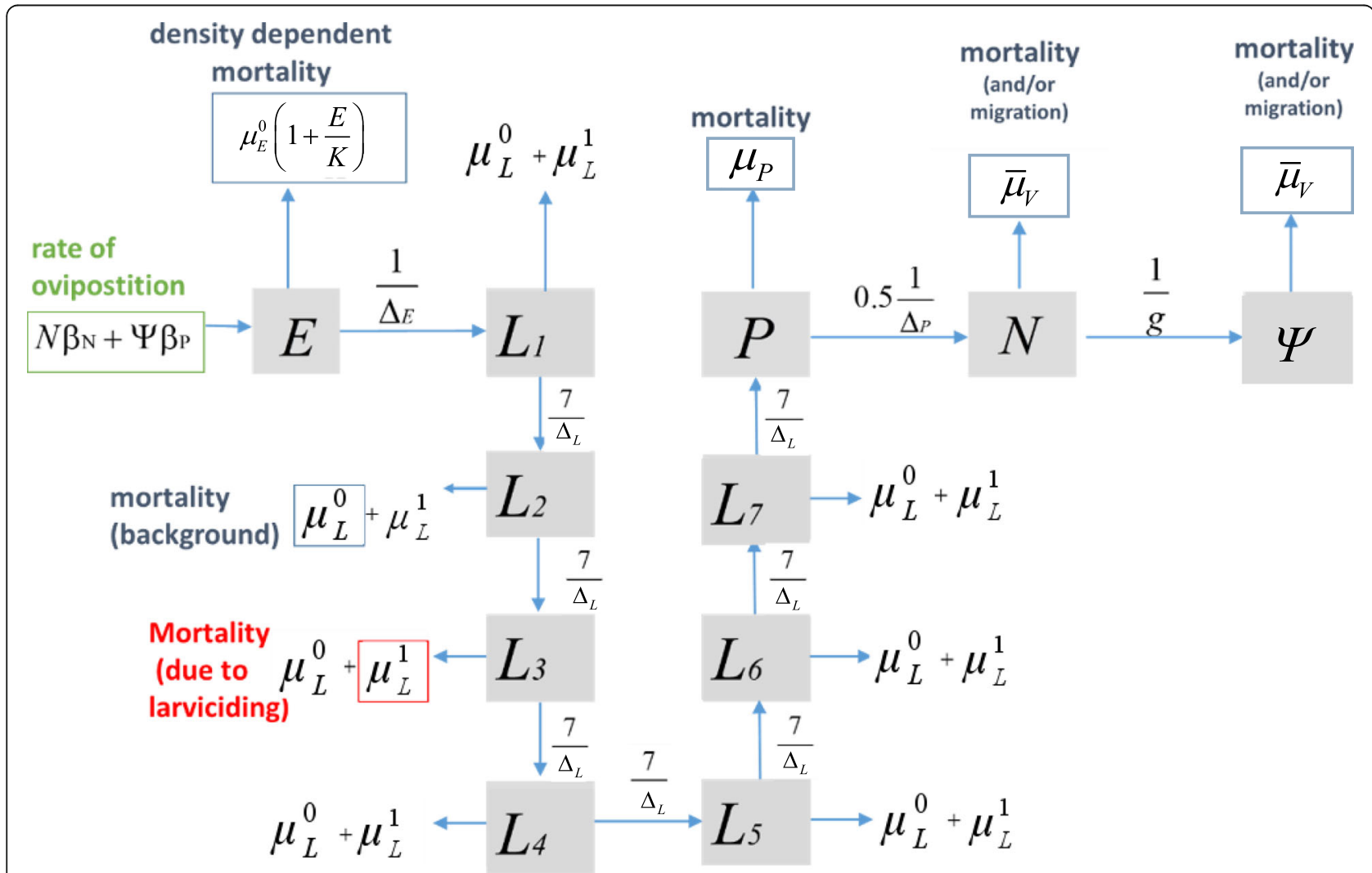

Fig. 1 Flow diagram of the model for the population dynamics of Simulium damnosum (s.l.) (SIMPOP). Boxes represent life-cycle states (eggs, larval instar stages 1-7, pupae, nulliparous and parous adults), arrows represent movement in and out of those states 
Table 2 State variables, expressions and (fixed) parameters of the SIMPOP model

\begin{tabular}{|c|c|c|c|c|}
\hline Notation & Definition and units & Expression & Mean & Reference \\
\hline$E\left(t, T_{W}\right)$ & $\begin{array}{l}\text { Mean no. of simuliid eggs at time } t \text { and } \\
\text { water temperature } T_{W}\end{array}$ & Eqn. (1) & - & [23] \\
\hline $\begin{array}{l}L_{1}\left(t, T_{w}\right) ; L_{i}\left(t, T_{W}\right) \\
2 \leq i \leq 7\end{array}$ & $\begin{array}{l}\text { Mean no. of 1st instar larvae and of } 2 \text { nd } \\
\text { to of } 7 \text { th instar larvae at } t \text { and } T_{W}\end{array}$ & Eqn. (2) & - & This study \\
\hline$P\left(t, T_{W}\right)$ & Mean no. of pupae at $t$ and $T_{W}$ & Eqn. (3) & - & [23] \\
\hline$N\left(t, T_{W}, T\right)$ & $\begin{array}{l}\text { Mean no. of nullipars at time } t \text {, water } \\
\text { temperature } T_{W} \text { and air temperature } T\end{array}$ & Eqn. (4) & - & [23] \\
\hline$\psi\left(t, T_{W}, T\right)$ & Mean no. of parous flies at $t, T_{W}$ and $T$ & Eqn. (5) & - & [23] \\
\hline$V\left(t, T_{W}, T\right)$ & Mean no. of vectors at $t_{1} T_{W}$ and $T$ & $N\left(t, T_{W} T\right)+\psi\left(t, T_{W}, T\right)$ & - & [23] \\
\hline$\Delta_{E}\left(T_{W}\right)$ & $\begin{array}{l}\text { Duration of egg stage at water } \\
\text { temperature } T_{W} \text { (days) }\end{array}$ & $11.493 \exp \left(-0.0701 T_{w}\right)$ & - & [23] \\
\hline$\Delta_{L}\left(T_{W}\right)$ & Duration of larval stage at $T_{W}$ (days) & $87.527 \exp \left(-0.0785 T_{W}\right)$ & - & [23] \\
\hline$\Delta_{p}\left(T_{W}\right)$ & Duration of pupal stage at $T_{W}$ (days) & $20.098 \exp \left(-0.0699 T_{W}\right)$ & - & [23] \\
\hline$\mu_{E}^{0}$ & $\begin{array}{l}\text { Background per capita rate of } \\
\text { eggs }\left(\text { day }^{-1}\right)\end{array}$ & - & 0.05 & [23] \\
\hline$\mu_{L}^{1}$ & $\begin{array}{l}\text { Mortality rate of larvae due to larviciding } \\
\left(\text { day }^{-1}\right)\end{array}$ & {$\left[-\ln \left(1-\varepsilon_{L}\right)-\mu_{L}^{0}\right]$} & - & This study \\
\hline$\beta_{N}$ & $\begin{array}{l}\text { Per nulliparous fly rate of oviposition } \\
\left(\text { day }^{-1}\right)\end{array}$ & $\frac{\varepsilon_{N}\left\{\exp \left[-\mu_{V}(T) g(T)\right]\right\}}{g(T)}$ & - & [23] \\
\hline$\beta_{p}$ & Per parous fly rate of oviposition (day ${ }^{-1}$ ) & $\frac{\varepsilon_{p} \mu_{V}(T)}{\left\{\exp \left[\mu_{V}(T) g(T)\right]-1\right\}}$ & - & [23] \\
\hline$\varepsilon_{N}$ & $\begin{array}{l}\text { Per capita mean no. of eggs per } \\
\text { nulliparous fly }\end{array}$ & $\begin{array}{l}\text { S. damnosum (s.s.)/S.sirbanum } \\
\text { S. squamosum }\end{array}$ & $\begin{array}{l}432 \\
492\end{array}$ & {$[23,62,63]$} \\
\hline$\varepsilon_{p}$ & $\begin{array}{l}\text { Per capita mean no. of eggs per } \\
\text { parous fly }\end{array}$ & $\begin{array}{l}\text { S. damnosum (s.S.)/S. sirbanum } \\
\text { S. squamosum }\end{array}$ & $\begin{array}{l}142 \\
215\end{array}$ & {$[23,62,63]$} \\
\hline$D B R$ & Daily biting rate $\left(\right.$ day $\left.^{-1}\right)$ & Eqn. (6) & - & - \\
\hline
\end{tabular}

$\frac{d N\left(t, T_{W}, T\right)}{d t}=\frac{0.5 P\left(t, T_{W}\right)}{\Delta_{P}\left(t, T_{W}\right)}-\left(\frac{1}{g(T)}+\bar{\mu}_{V}(T)\right) N\left(t, T_{W}, T\right)$

$$
\frac{d \Psi\left(t, T_{W}, T\right)}{d t}=\left(\frac{1}{g(T)}\right) N\left(t, T_{W}, T\right)-\bar{\mu}_{V}(T) \Psi\left(t, T_{W}, T\right) .
$$

The equation for the daily biting rate, $D B R$, is,

$$
\begin{aligned}
\operatorname{DBR}\left(t, T_{W}, T\right) & =\frac{V}{H}\left(\frac{h}{g(T)}\right) \\
& =\frac{N\left(t, T_{W}, T\right)+\Psi\left(t, T_{W}, T\right)}{H}\left(\frac{h}{g(T)}\right),
\end{aligned}
$$

where $V$ is the total biting vector population, comprising nulliparous and parous female flies; $H$ is the human population density, $h$ is the proportion of blood meals taken on humans (or human blood index) and $g(T)$ is the duration of the gonotrophic cycle (the average period between two consecutive blood meals) which would be influenced by environmental temperature; in practice we do not have an explicit expression for this relationship but we have included it in the equations above for the sake of completeness. We assume gonotrophic concordance, i.e. one blood meal for the development of one batch of eggs.

\section{Addition of loss function}

The adult mortality term $\bar{\mu}_{V}(T)$ represents an (estimated) composite parameter instead of a simple vector mortality rate, due to the possibility of adult fly migration in and out of the study sites, which has been observed in previous field studies in savannah settings $[25,33,34]$. For the modelling presented here we only considered emigration (parameter Em). In [23], a relationship between adult fly mortality and air temperature was established for Asubende, which was used here as part of the loss function for the savannah settings (Table 1). However, due to the context-specific nature of this parameter, this relationship was not used for forest adult fly mortality; instead the composite loss function was estimated for this setting.

\section{Addition of larval instar stages}

Seven larval instar stages were added, in place of a single larval compartment, better reflecting the life-cycle of 
blackfly aquatic stages [35]. This has been used to model increased realism in developmental times in other population dynamics models of insect disease vectors, for example Anopheles gambiae [36]. Otherwise a proportion of larvae leave the larval compartment much more quickly than occurs in reality; this is because the assumption of a constant rate of progression through model compartments leads to an exponential distribution of time spent in the larval compartment. This then affects the numbers that progress to the next compartment and the effect of larviciding on population dynamics.

\section{Time-dependent mortality due to larviciding}

An extra-mortality term for blackfly larvae was introduced, $\mu_{L}^{1}$, which represents excess larval mortality due to larviciding (in addition to the background larval mortality rate $\mu_{L}^{0}$ ). The model considers a larviciding regime carried out at regular intervals, with $\mu_{L}^{1}$ representing a near instantaneous death of blackfly larvae which come into contact with the larvicide. Larvicidal efficacy, $\varepsilon_{L}$, is defined as 1 minus the proportion of larvae surviving one day after deploying the insecticide, reflecting the rapid activity of insecticides such as temephos, which has been shown to be highly efficacious against $S$. damnosum (s.l.) larvae at concentrations giving $0.05 \mathrm{mg} / \mathrm{l}$ at high river discharges ( $>25$ cubic metres/second) and at $0.1 \mathrm{mg} / \mathrm{l}$ at low discharges (when insecticide carry is reduced) [37]. Although temephos efficacy has been shown to be variable in the field [37], laboratory studies on S. damnosum (s.l.) in Tanzania [38] have found an efficacy of 99-100\%. Field studies of larvicidal efficacy during contemporary ground-based vector control strategies found values between 93-96\% [26], whereas other models [39] have considered scenarios with $99 \%$ efficacy. In practice, inadequately implemented larviciding regimes or regimes in very difficult to reach areas are likely to have lower efficacies.

\section{Re-estimation of carrying capacity, $K$}

Following [23], and in order to stabilise the population, the density-dependent mortality of eggs is expressed in terms of the carrying capacity of adult vectors $K$, i.e. $\mu_{E}(K)=\mu_{E}^{0}\left(1+\frac{E(t, T)}{K}\right)$, where $\mu_{E}^{0}$ is the background mortality rate of eggs. Due to the modifications of the model implemented here, a new relationship between carrying capacity, $K$, and the equilibrium number of adult (female) flies, $V^{*}$, was derived by setting the equations for the blackfly population dynamics to zero to obtain equilibrium expressions for each stage (see equation 4.9 of [23]). Details of this derivation can be found in Additional file 1 (Re-estimating carrying capacity, K).

\section{Calibration of SIMPOP for different ecological/taxonomic contexts}

Using the datasets described above, the model was calibrated for savannah and forest settings by fitting the model, respectively, to the Asubende and the Sanaga Valley data using Approximate Bayesian Computation $(\mathrm{ABC})$ methods implemented with the $a b c \mathrm{R}$ package [40]. The methods are fully described in Additional file 1 (Description of approximate Bayesian computation for parameter estimation).

Briefly, parameter sets were sampled from prior distributions informed by the published literature. Table 1 lists the estimated parameters and their prior distributions alongside the relevant references used to inform these priors. The majority of the parameters were given informative priors (i.e. those with values and ranges well established in the literature, e.g. larvicidal efficacy), whilst others (e.g. the adult fly loss function) were given uninformative/vague priors. Parameter sets drawn from these priors were inputted into SIMPOP to produce simulations of the mean number of bites per person per day over time and, from a Poisson distribution, to yield simulated datasets of the number of bites per person per day.

For each simulation, from a particular parameter set, summary statistics were computed from the simulated data and compared to summary statistics from the actual data using a distance measure defined by the Poisson log likelihood. Parameter sets yielding simulated datasets with log likelihoods sufficiently close (defined by an acceptance or threshold parameter, Additional file 1, Description of approximate Bayesian computation for parameter estimation) to the log likelihood of the observed data were considered as samples from the approximate posterior distribution (posterior). This was repeated for 1500 parameter sets drawn from the prior distributions. The version of $\mathrm{ABC}$ inference used for this analysis also employs a post-hoc machine-learning regression technique to improve the approximation of the posterior. In particular, we made use of neural networks [41] to correct for the imperfect match between the accepted and observed likelihoods. Rather than simply setting a tolerance threshold and rejecting a proportion of parameter values away from the observed likelihood, this approach considers how similar likelihoods of accepted parameter sets are to observed likelihoods. When just a tolerance is used, some parameters may be included which are quite far away from observed likelihood and useful information from the summary statistics is lost.

Parameter posteriors were summarised using the mean and the associated ninety five percent credible interval (95\% CI). The model, calibrated either with data from Ghana (savannah setting) or Cameroon (forest setting) was then validated against the corresponding independent datasets Burkina Faso/Côte d'Ivoire (savannah) and Bioko (forest). 


\section{Scenario analysis}

Once SIMPOP was calibrated for S. damnosum (s.s.) savannah settings and S. squamosum B forest settings, the number of larvicide applications and the interval between larvicide applications were varied to evaluate effectiveness and identify optimal treatment strategies. Effectiveness was quantified by three outcome measures, namely, (i) the proportion of bites averted, defined as the proportion of bites prevented given the expected number of bites that would have been received during the treatment period in the absence of control; (ii) the proportional reduction in $D B R$, measured as 1 minus the ratio between the $D B R$ one day after the cessation of larviciding and the endemic pre-intervention baseline $D B R$; (iii) the time to repopulation or bounce-back, defined as the number of days between one day after cessation of larvicidal operations and the vector biting rate returning to pre-intervention baseline levels. Hence, the most effective regimens were those with the highest proportion of bites averted, the greatest proportional reduction in $D B R$, and the longest time to bounce-back of adult fly populations.

\section{Exploring the effect of insecticide efficacy, endemic} (pre-intervention) vector density and ecological factors on the impact of larviciding on adult fly biting rates

We explored the effect of varying individually several context-specific parameters on the output of the fitted model to determine their potential impact on groundbased larviciding control programmes in a wider range of contexts. These parameters were: (a) the preintervention baseline daily biting rate, $D B R^{*}$ (varied between 100 and 900 bites/person/day); (b) the air temperature (varied between 25 and $28{ }^{\circ} \mathrm{C}$, and its corresponding variation in water temperature between 23.6 and $26.5{ }^{\circ} \mathrm{C}$ ); (c) the length of the gonotrophic cycle (varied between 2.5 and 4 days); and (d) the larvicidal efficacy (varied between 50 and 99.5\%). These parameters were chosen on the basis of either being important in the ecology and population dynamics of Simulium spp. (DBR*, air temperature and length of gonotrophic cycle), or being programmatically relevant (larvicidal efficacy; although intrinsic susceptibility to larvicidal insecticides may also be influenced by cytospecies-specific factors which were not considered explicitly here). Other parameters were also varied individually to explore their impact on model outputs (Additional file 1, Sensitivity of model to changes in parameter values). (Notice that we refer to observed daily biting rates as DBRs to denote the data, whereas we use $D B R$ when referring to modelled biting rates; in particular, $D B R^{*}$ denotes the modelled pre-intervention baseline/equilibrium daily biting rate.)

\section{Results}

Calibration and validation

The calibrated model captured the majority of observed DBRs within the 95\% CIs for both savannah (dominant vector S. damnosum (s.s.)) and forest (dominant vector S. squamosum B) contexts (Fig. 2a, b). The validation, where only the pre-intervention equilibrium $D B R^{*}$, air and water temperature were altered to reflect local conditions (Table 1), also captured well the observed data (Fig. 2c, d). Pairs plots (Additional file 1, Pairs plots of parameter estimates) suggested that none of the parameters were strongly correlated, with the exception of, for the forest parameterisation, the adult loss function $\left(\bar{\mu}_{V}(T)\right)$ and the background (in the absence of larvicide) larval mortality rate $\left(\mu_{L}^{0}\right)$, as the relationship between temperature and adult fly mortality is less well characterised for this context (i.e. compared to the savannah setting [23]), and as a result the two terms were not fully identifiable.

\section{Scenario analysis \\ Larvicidal efficacy and effectiveness of implementation scenarios}

Efficacy and effectiveness in savannah settings The mean of the estimated posterior of larvicidal efficacy in the Asubende study was $99 \%$ for the savannah-calibrated model. This model predicted a proportional reduction in $D B R$ (one day after the last larvicidal treatment compared to one day before the first treatment) after 4 or 10 larviciding treatments every 7 days (i.e. weekly) of, respectively, $97 \%$ and $100 \%$. Extending the interval between treatments to 14 days (i.e. every 2 weeks) and 21 days (i.e. every 3 weeks) resulted in lower $D B R$ reductions, of $89 \%$ and $78 \%$, respectively for 10 larvicidal applications (Fig. 3a).

Similarly, extending the interval between treatments from 7 to 14 days resulted in a smaller proportion of bites averted (60\% compared to $69 \%$ following 10 treatments), and a faster rate of adult blackfly repopulation (158 compared to 244 days to repopulation following 10 treatments, indicative of a smaller reduction in $D B R$ ). Extending the between-application interval from 14 to 21 days resulted in little discernable difference in these effectiveness measures (Fig. 3a, b, c), with a similar proportion of bites averted and a moderately longer time to re-population (60\% bites averted and 158 days to repopulation for 10 treatments with 14-day intervals compared to $61 \%$ bites averted and 138 days to re-population for 10 treatments with 21-day intervals).

Efficacy and effectiveness in forest settings The mean of the estimated posterior of larvicidal efficacy was $96 \%$ in the Sanaga Valley trial [26] for the forest-calibrated 

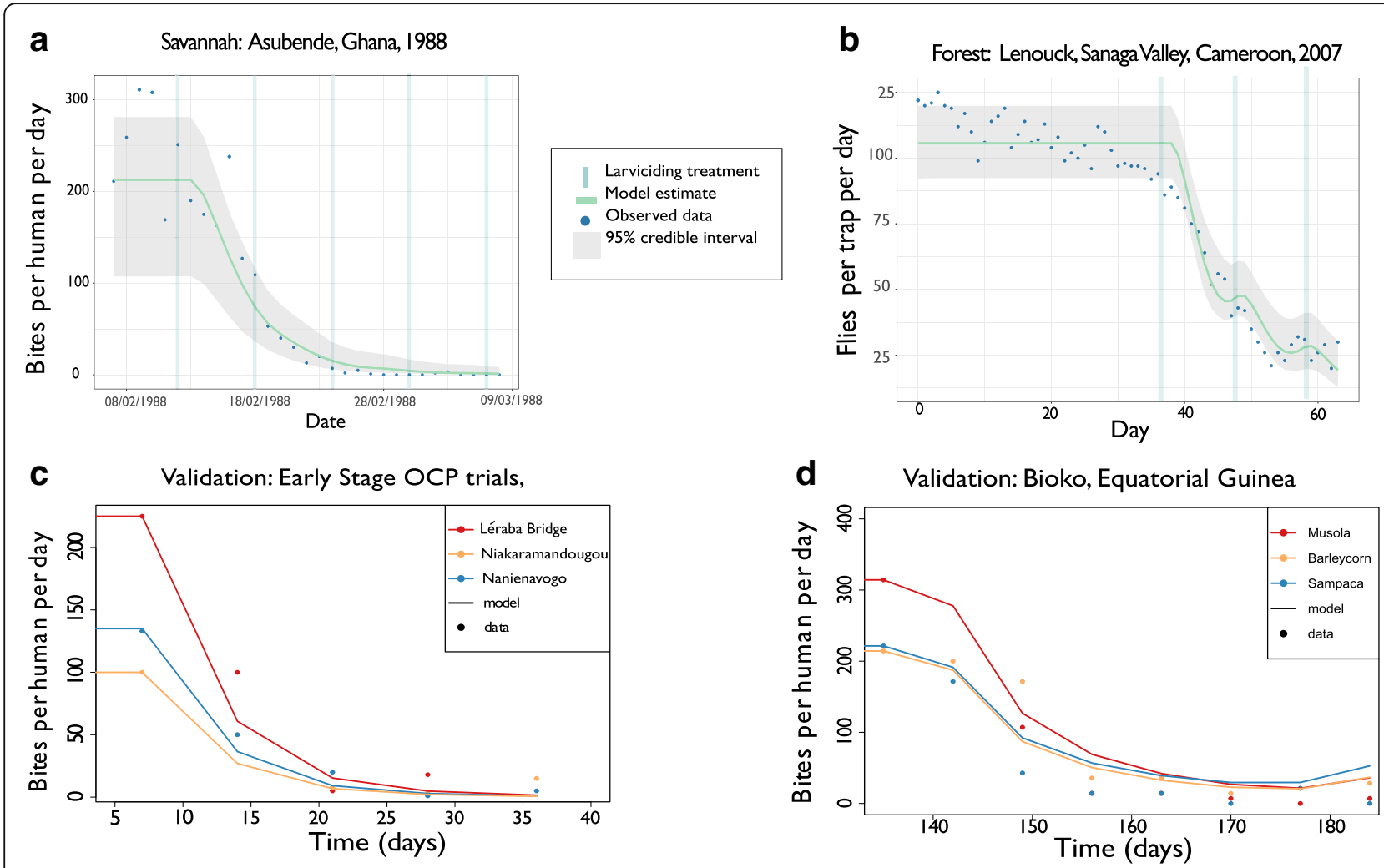

Fig. 2 Model calibration and validation. a Calibration of model for savannah settings by fitting SIMPOP to data from Asubende, river Pru, Ghana, corresponding to 7-day intervals of aerial larviciding. $\mathbf{b}$ Calibration for forest settings by fitting the model to data from Lenouck, Sanaga river valley, Cameroon, corresponding to 10-day intervals of pirogue (boat)-based larviciding. c Validation of savannah-calibrated model against data from weekly (aerial) larviciding in OCP sites in Burkina Faso and Côte d'Ivoire. $\mathbf{d}$ Validation of forest-calibrated model against data from weekly larviciding by boat in forest areas of Bioko. In the validation datasets $(\mathbf{c}, \mathbf{d})$, local values of pre-intervention equilibrium DBR and air/water temperature were used but all remaining parameters were unchanged

model. Predicted patterns of effectiveness for different larviciding implementation scenarios were similar to those for the savannah context and are presented in Additional file 1 (Results of scenario analysis).

Impact of larvicidal efficacy Setting larvicidal efficacy to $93 \%$, a more conservative but realistic value for local vector control during the pilot phase of implementation [26], the model predicted proportional reduction in $D B R$ was $96 \%$ following 10 weekly treatments for both savannah (Fig. 3d, e, f) and forest contexts (Additional file 1, Results of scenario analysis). At a pre-intervention baseline $D B R$ of $400 \mathrm{bites} /$ person/day (the average equivalent DBR observed in three forest sites in South-West Cameroon [42] where focal vector control is being implemented by the CouNTDown consortium (http://www.count downonntds.org/our-research/integrated-control-strategy1-macro-vector/, L. Hamill, pers. comm.), this equates to a predicted reduction in $D B R$ to approximately 16 bites/person/day. (It must be noted that although Matthews et al. [26] found efficacies ranging between
93 and 97\%, we chose the more conservative option of 93\% for a realistic implementation efficacy.)

At 70\% larvicidal efficacy, representing greater programmatic difficulties, poorer implementation, implementation in more inaccessible areas, or indeed where efficacy is dwindling due to evolving insecticidal resistance, the measures of effectiveness were lower (Fig. 3g, h, i). With this efficacy, the model predicted that after a total of 10 larvicide applications at intervals of 7 days in a savannah setting, the $D B R$ would be reduced by $67 \%, 33 \%$ of bites would be averted and the time for the adult blackfly population to re-populate to pre-intervention levels would be 125 days. The corresponding estimates in the forest context were $65 \%, 33 \%$ and 123 days, respectively (Additional file 1, Results of scenario analysis).

The results of the scenario analysis in relation to optimal and minimal intervention design requirements to achieve specified target results are summarised in Table 3. For a larvicidal efficacy of $93 \%$, the minimum number of weekly treatments required to achieve at least a 95\% reduction in DBR would be, respectively, 8 and 9 for savannah and forest contexts. For the same larvicidal 


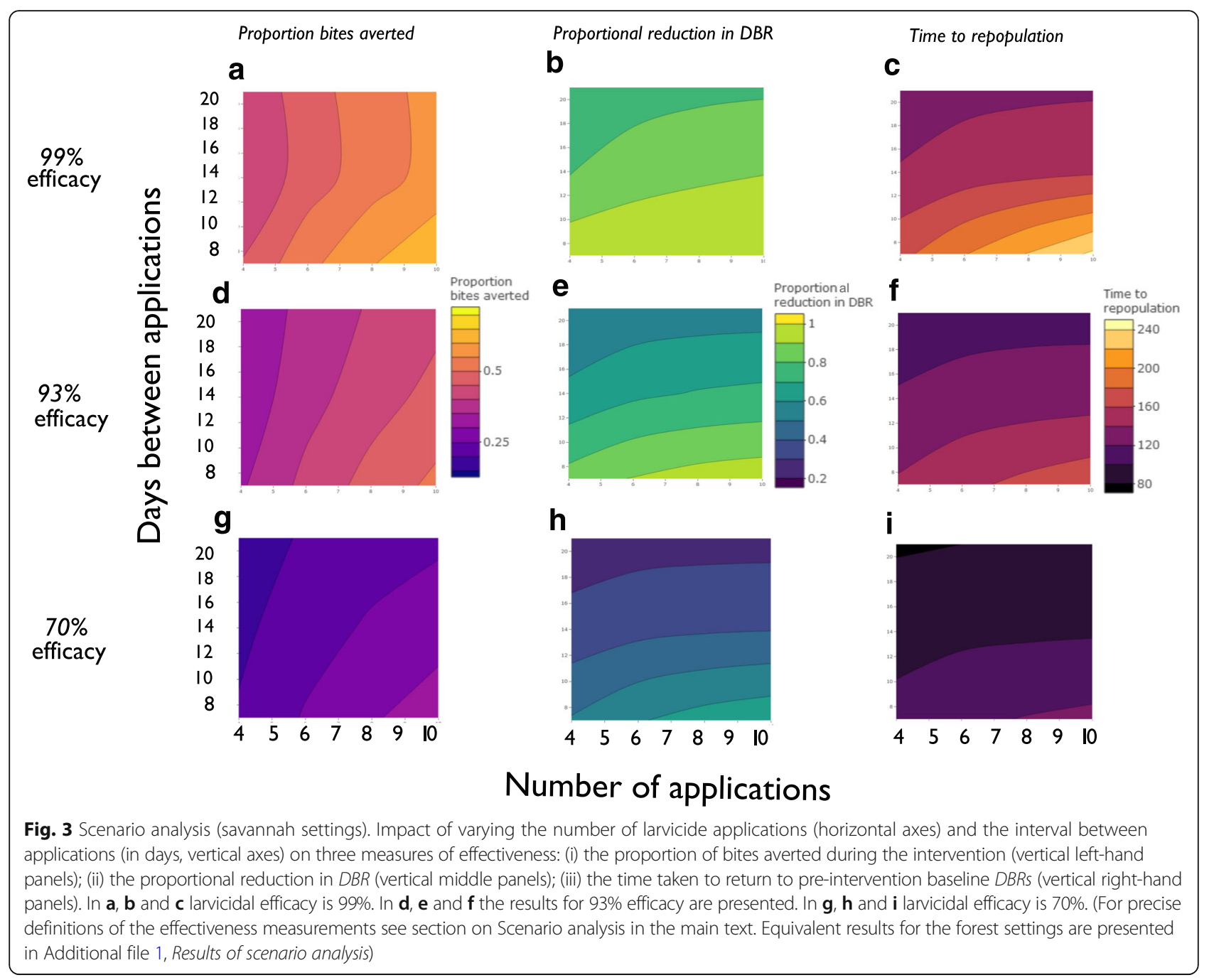

efficacy, and to delay the time to bounce-back/repopulation (for the fly density to reach baseline levels) to at least 200 days, 16 and 8 weekly treatments would be required in savannah and forest contexts, respectively.

\section{Pre-intervention daily biting rate, temperature and gonotrophic cycle length}

When larvicidal efficacy is very high (99\%), similar and substantial $D B R$ reductions can be achieved regardless of initial pre-intervention biting rates (Fig. 4a, upper panel). However, when efficacy is reduced (to $80 \%$ ), higher DBRs do not decline by as much (Fig. 4a, lower panel). Water temperature (related to air temperature) and gonotrophic cycle length also have important, non-linear effects on the effectiveness of larviciding on DBRs (Fig. 4b, c), with lower temperatures and therefore longer gonotrophic cycles resulting in slower rates of adult fly re-population. Figure $4 \mathrm{~d}$ illustrates the impact of larvicidal efficacy on modelled $D B R$.

\section{Discussion}

Vector biting rate is an important determinant of transmission intensity, endemicity level (measured in terms of O. volvulus microfilarial prevalence and intensity) and feasibility of elimination of onchocerciasis with the current CDTI strategy. In areas of high pre-intervention baseline infection endemicity, it has been suggested that vector control could be used as an adjuvant and complementary intervention strategy [13]. Modelling results using EPIONCHO and ONCHOSIM [43] suggest that in such settings, vector control could be used in conjunction with ivermectin MDA to enhance effectiveness or to consolidate the gains made towards the path of onchocerciasis elimination. However, in both models, vector control has been implemented somewhat crudely, by instantaneously reducing adult biting rates to given lower levels for a (usually prolonged) period. In practice, the application of larvicidal insecticides will effect dynamic changes in both aquatic and aerial blackfly stages, with adult fly populations recovering gradually after 


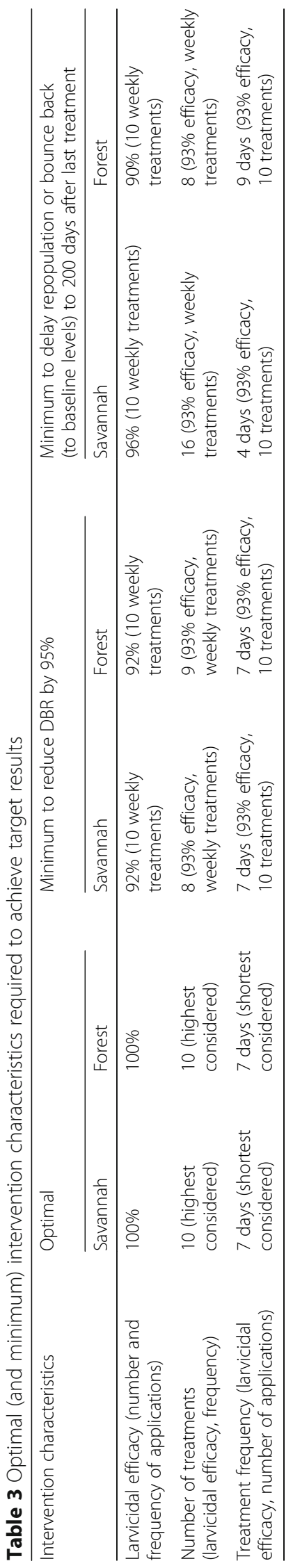


a
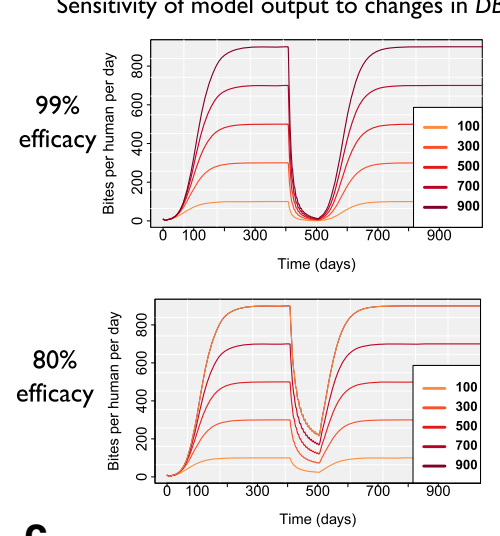

C

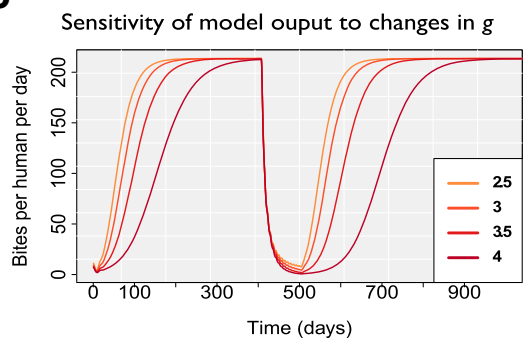

b

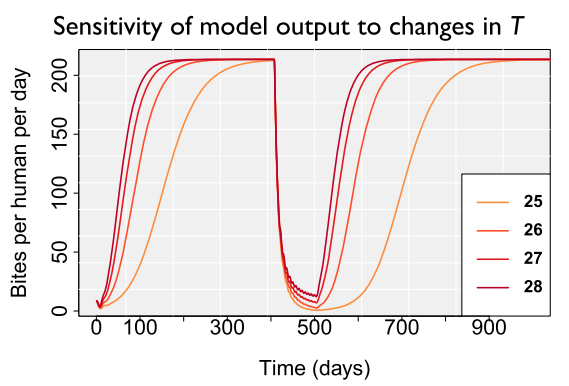

d Sensitivity of model output to changes in efficacy, $\varepsilon_{L}$

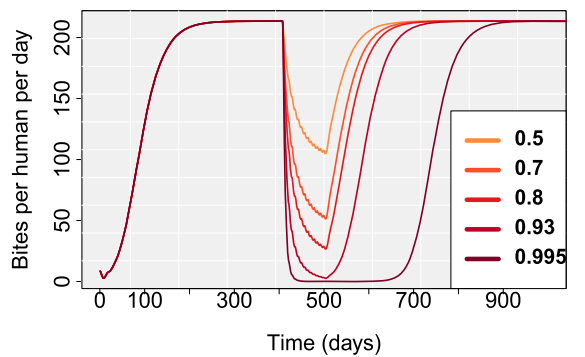

Fig. 4 Sensitivity of model output to a pre-intervention daily biting rate $D B R^{*} ; \mathbf{b}$ air temperature, $T$ (to which water temperature is related via $T_{W}=0.9844 T-1.0352$, see [23]); c gonotrophic cycle length, $g$; and $\mathbf{d}$ larvicidal efficacy, $\varepsilon_{L}$

cessation of operation. Also, programmes considering the implementation of (local, ground-based) vector control may do so for variable periods depending, among other things, on seasonal feasibility of implementation and vector ecology. (For instance, ground-based larviciding targeted at $S$. neavei in the Kashoya-Kitomi focus of western Uganda was deployed monthly for 3 years for a total of 36 applications [21]. In the Bahr El Ghazal region of south western Sudan, temephos was applied for one annual transmission period, with ensuing reductions of $70 \%$ in vector biting and of $80 \%$ in transmission at sites with the highest pre-control levels [37]).

In order to investigate more realistic options for modelling vector control, we have extended our previous blackfly population dynamics model [23] to explore the effects of larviciding on the population dynamics and biting rates of $S$. damnosum (s.l.) in West/Central African savannah and forest contexts. The results suggest that when larvicidal efficacy is high, the blackfly DBRs could be reduced to very low levels after 10 weeks of larviciding, even in areas of high pre-intervention blackfly population density (indicative of conditions with a high propensity for onchocerciasis transmission). However, our model also indicates that the magnitude of DBR reduction would be very sensitive to the larvicidal efficacy that can be achieved. We explored a range of efficacy values because, in practice, final net efficacy will depend on the type of insecticide, the local ecological and accessibility conditions of the breeding sites, and the susceptibility of the aquatic stages of the local vector species (which could decrease under insecticide selection pressure). Locally-specific parameters such as water temperature did not affect the rate of DBR decline following larviciding at high larvicidal efficacies but did affect rates of adult blackfly repopulation. Hence, the effectiveness of short-term focal vector control programmes in sustaining low blackfly population biting densities is likely to vary with the local ecology and possibly also on the dominant simuliid cytospecies. Vector control is likely to be most effective when a high larvicidal efficacy can be ensured, where breeding site water temperatures are lower and life-cycles (including gonotrophic cycles) are longer (e.g. in more shaded breeding sites, those located at higher altitudes).

Even in the absence of concomitant treatment of the onchocerciasis-affected human population, vector biting rate plays an important role in the persistence of onchocerciasis. For a given simuliid vector competence, vectorial capacity (including the propensity to feed on humans) and the values of other vector- and parasitedependent population biology parameters, there is a threshold biting rate $(T B R)$ below which onchocerciasis would not persist endemically. This $T B R$ is related to the basic reproduction number of the parasite in a given 
environment $\left(R_{0}\right)$, and for savannah $O$. volvulus-S. damnosum combinations, it has been estimated to vary between 230 and 2300 bites/person/year, with a mean of approximately 700-800 [44-47]. This would represent an average of 2 bites/person/day (and a range between 1 and 6) in the absence of anti-parasitic interventions, and could be even lower in forest O. volvulus-S. damnosum combinations due to higher vector competence [48] and stronger anthropophagy [49]. More likely, vector control will be deployed as a complementary treatment strategy, and modelling studies have indicated that in the presence of MDA treatment, the value of the TBR will increase, emphasizing the beneficial role of vector control. These predicted shifts towards higher TBR values highlight avenues for accelerating elimination of the infection by including vector control, even when conducted at a relatively low level of effectiveness [47]. In the following sections, we discuss the role of larvicidal efficacy, vector ecology and overall vector control effectiveness.

\section{Larvicidal efficacy}

The field efficacy of a larviciding approach is crucial to delivering effective vector control. Even larvicides such as temephos with near $100 \%$ efficacy in the laboratory [38] will inevitably have somewhat lower operational efficacy. Recent pilot focal vector control schemes have achieved efficacies of 93-96\% [26] and for such high operational efficacies, our modelling results indicate that weekly larviciding for 10 weeks would reduce DBRs to very low levels regardless of the pre-control population density of blackflies. However, at lower larvicidal efficacies, and specifically in settings with high blackfly population densities, reductions in DBRs may never reach epidemiologically acceptable levels (particularly with respect to reducing nuisance biting to tolerable levels or increasing the TBR sufficiently to increase the likelihood of elimination) even after longer periods of vector control. It is reasonable to assume that high reported operational efficacies could be replicated elsewhere with careful planning (including consideration of the seasonality of breeding sites, river volume and flow, and the spatial spread of insecticide) and judicious implementation (including monitoring of insecticidal efficacy). Nonetheless, achieving and sustaining high operational/ field efficacy is a priority when designing larviciding schemes. Therefore, measures for monitoring efficacy and responding to emerging larvicidal resistance should be put in place from the outset. Resistance to temephos and other larvicides arose rapidly during the aerially-delivered larvicidal applications during the OCP [50-52], highlighting the importance of careful monitoring as well as of forward planning and implementation of larvicide rotation schedules should the need arise. Efficacy can be monitored through sampling and measuring density of vector larvae at baseline before intervention in control and treated areas and 24 hours, 48 hours and then weekly for several months following treatment, again in control and treatment areas [53]. However, unlike mosquito larval monitoring, density for simuliids is generally measured on a 5-point abundance scale, from to ++++ , referring to absent, scarce, few, common, heavy, due to the difficulties in counting individual simuliid larvae [54].

\section{Ecology and effectiveness}

The time taken for DBRs to return to pre-intervention levels following cessation of larviciding varies notably with adult and larval mortality and air/water temperature (see Additional file 1, Sensitivity of model to changes in parameter values), indicating that the effectiveness in sustaining reductions in blackfly population densities will vary among locales. The forest parameterisation of the model resulted in greater proportional reductions in the $D B R$ following larviciding, despite a lower estimated efficacy. In addition, the effects of larviciding were sustained for longer than in the model calibrated with savannah simuliid species, with longer times to repopulation (again, despite the lower estimated larvicidal efficacy). This is likely to be the result of lower temperatures in forested areas affecting life-cycle and gonotrophic cycle length as our estimates did not reveal large differences in adult or larval mortality. These results are promising for controlling vectors in (forest) loiasis-onchocerciasis co-endemic areas where CDTI is not effective or cannot be implemented because of the risk of SAEs following ivermectin treatment of individuals with high $L$. loa microfilaraemia $[18,19]$. However, implementation of larviciding may be more difficult in forest compared to savannah areas because the potentially more difficult access to rivers and tributaries. Hence, in such areas it may be harder to achieve high levels of field/operational efficacy. Given that our model highlights the importance of larvicidal efficacy on achieving substantial $D B R$ reductions, this is a very important consideration, and one which requires expertise from field practitioners and vector ecologists. Additionally, further research needs to be conducted linking SIMPOP and EPIONCHO [22] to explore the minimum level of larvicidal efficacy that should be aimed at when deploying intervention packages including both human treatment and vector breeding site treatment.

\section{Future directions}

We are planning to integrate SIMPOP with EPIONCHO, to permit detailed exploration of the impact of vector larviciding on onchocerciasis transmission dynamics, control and elimination when chemotherapeutic interventions are combined with vector control. Modelling projections 
based on distribution of ivermectin [43] indicate that onchocerciasis elimination will not be achieved in reasonable timescales in hyperendemic/holoendemic areas, where blackfly biting is very intense and, therefore, vector control has been proposed as an ATS to accelerate progress towards elimination (and reduce nuisance biting) [13]. As discussed, the impact of vector control has generally been modelled (but see [55]) by reducing the annual biting rate of the blackfly vector population over the duration of control. This highly simplified approach does not lend itself to modelling explicitly the effect of larviciding (at different durations and frequencies) on blackfly population dynamics. Hence, the model presented here could contribute to improving projections of the impact of suites of interventions targeting onchocerciasis elimination. These suites could include, among others, optimisation of the frequency and timing of microfilaricidal treatment (e.g. MDA with ivermectin or moxidectin) in relation to natural vector seasonality [56] and vector control; the combination of available and novel macrofilaricides (e.g. anti-Wolbachia therapies) with vector control (as currently being trialled by the CouNTDown Consortium), and the addition of vector control in areas with suboptimal responses to ivermectin [57].

The model presented here for forest areas does not distinguish between adult mortality or net egress/ingress to and from neighbouring sites. However, assuming that the relationship between temperature and adult fly mortality developed for the Asubende savannah context [23] holds generally, including for forest contexts, the mean excess loss due to reasons other than mortality (i.e. emigration) could be estimated. Reinvasion of vectors from surrounding areas not under vector control was commonplace in OCP savannah sites [33, 34], justifying its incorporation into the model presented here. Nonetheless, designs of control areas should consider risk of migration/source-sink population dynamics. Future models, if spatially structured, could potentially model the movement of vectors among proximate populations and transmission zones and evaluate the impact this would have on vector control.

Field studies at key sites would provide important information for planning vector control. Data on the distribution of $S$. damnosum (s.l.) cytotaxa across Africa is somewhat limited, with the exception of some detailed country-specific studies [58-60]. This is important as different cytotaxa have varying vectorial capacities, fecundities, mortalities and habitats. Some may be of much greater concern for onchocerciasis transmission. Given the findings of different repopulation rates in different contexts, these field data would be important to capture locale-specific population dynamics, permitting model calibration for a variety of ecological settings.

\section{Conclusions}

Our modelling findings indicate that focal vector control is likely to be effective in breeding sites where a high larvicidal efficacy can be achieved and maintained, applications can be delivered regularly and ideally weekly (in S. damnosum (s.l.) breeding sites), and sustained durations can be ensured. In addition to these programmatic factors, ecological features such as lower breeding site water temperatures, longer blackfly life-cycles, or longer gonotrophic cycles in the dominant Simulium cytospecies may also increase effectiveness. The refined SIMPOP model developed here has clear applications to the design of blackfly control strategies in African forest and savannah settings. Future work to integrate the model into O. volvulus transmission dynamics models, particularly EPIONCHO, will permit evaluation of the epidemiological impact of combined anti-vectorial and anti-parasitic interventions aiming at controlling and eliminating human onchocerciasis.

\section{Additional file}

Additional file 1: Description of the calculation of carrying capacity, approximate Bayesian computation (ABC) methods and sensitivity/scenario analyses. Re-estimating carrying capacity, K. Description of approximate Bayesian computation for parameter estimation. Sensitivity of model to changes in parameter values. Pairs plots of parameter estimates. Results of scenario analysis. (PDF 641 kb)

\section{Abbreviations}

95\% Cl: Ninety five percent credible interval; ABC: Approximate Bayesian computation; APOC: African Programme for Onchocerciasis Control;

ATS: Alternative treatment strategy; CDTI: Community-directed treatment with ivermectin; DALY: Disability-adjusted life year; DBR: Daily biting rate; MDA: Mass drug administration; NTD: Neglected tropical disease;

OCP: Onchocerciasis Control Programme in West Africa; ODE: Ordinary differential equation; $R_{0}$ : Basic reproduction ratio; s.l: sensu lato; s.s.: sensu stricto; SAE: Severe adverse event; SIMPOP: SIMuliid POPulation dynamics model; SSA: Sub-Saharan Africa; TBR: Threshold biting rate; US\$: United States dollar; WHO: World Health Organization; YIF: Yaoundé Initiative Foundation

\section{Acknowledgements}

Our thanks go to Dr John B. Davies for providing guidance on the Grechan dataset as published in Davies et al. [61] and used in initial work on the model. We are also grateful to the CouNTDown team (Liverpool School of Tropical Medicine) for organizing an 'Entomologists Meeting' in July 2016, during which a preliminary version of the modelling results was presented, for invaluable discussion, feedback and insights into the preparation of plans for ground-based blackfly control from experts in the field. In particular, Louise Hamill shared information on implementation of larviciding as a complementary treatment strategy in South-West Cameroon.

\section{Funding}

IR conducted the research for this paper during the MRes component of a PhD studentship funded by the Wellcome Trust and would like to thank the MRC Centre for Outbreak Analysis and Modelling at Imperial College London (https://www.imperial.ac.uk/mrc-outbreaks/). MGB thanks the Wellcome Trust (www.wellcome.ac.uk, grant numbers 085133/Z/08/Z and 092677/Z/10/Z) and the Royal Society (https://royalsociety.org/, Capacity Building Africa Award). MW and MGB thank the NTD Modelling Consortium (http://www.ntdmodelling.org/) funded by the Bill \& Melinda Gates Foundation (https://www.gatesfoundation.org/) in partnership with the Task Force for Global Health (https://www.taskforce.org/). The funding bodies had no input into the design, analysis, conclusions and decision to publish of the study. 


\section{Availability of data and materials}

The data which the model was fitted to, or validated with, are presented in the figures that summarise the results. The model and parameter values are presented in the equations, flow diagram and tables accompanying the article.

\section{Authors' contributions}

Conceived and designed study: MGB, MW, RAC and IR. Advised on methods: $S B, M W$ and MGB. Carried out study: IR. Wrote paper: IR, MGB and MW. Provided data: RAC, GAM and PBN. All authors read and approved the final manuscript.

\section{Authors' information}

IR is a PhD student at the Department of Infectious Disease Epidemiology, School of Public Health, Imperial College London, with a particular interest in the ecology and epidemiology of vector-borne diseases. MW is a Lecturer (Assistant Professor of Epidemiology) at the Royal Veterinary College and Honorary Lecturer at Imperial College London, focusing on the statistical and dynamic modelling of parasites and vectors. RAC is a Professor of Tropical Zoology at the Natural Resources Institute (NRI) of the University of Greenwich, with expertise in disease vector and non-vector insect ecology and control; he is also a Visiting Professor at the Department of Infectious Disease Epidemiology, Imperial College London. SB is a Lecturer in Geostatistics at Imperial College London working on spatial statistics and epidemiology of infectious diseases of poverty. PBN is the Managing Director of the Yaoundé Initiative Foundation (YIF, based in Cameroon and Imperial College London), originally a specialist in integrated pest management from Wye College, London and with practical and professional administrative African experience. GAM is Emeritus Professor at the Department of Life Sciences (Silwood Park), Imperial College London. DB is the Technical Manager for the YIF, working on vector control. HMD is a pest and vector management specialist with experience in management, research and training for poverty reduction at the NRI, University of Greenwich, with secondments at Imperial College London. PBN, GAM, HMD and TLW are founder members of the YIF. MGB is a Professor of Neglected Tropical Diseases at the Department of Infectious Disease Epidemiology, Imperial College London working on the population biology and transmission dynamics of vector-borne and helminth infections.

\section{Ethics approval and consent to participate}

Not applicable.

\section{Competing interests}

The authors declare that they have no competing interests.

\section{Publisher's Note}

Springer Nature remains neutral with regard to jurisdictional claims in published maps and institutional affiliations.

\begin{abstract}
Author details
${ }^{1}$ MRC Centre for Outbreak Analysis and Modelling, Department of Infectious Disease Epidemiology, School of Public Health, Faculty of Medicine (St Mary's campus), Imperial College London, Norfolk Place, London W2 1PG, UK. ${ }^{2}$ London Centre for Neglected Tropical Disease Research (LCNTDR), Department of Pathobiology and Population Sciences, Royal Veterinary College, Hawkshead Lane, Hatfield, Hertfordshire AL9 7TA, UK. ${ }^{3}$ London Centre for Neglected Tropical Disease Research (LCNTDR), Department of Infectious Disease Epidemiology, School of Public Health, Faculty of Medicine (St Mary's campus), Imperial College London, Norfolk Place, London W2 1PG, UK. ${ }^{4}$ Natural Resources Institute, Department of Agriculture, Health \& Environment, University of Greenwich, Central Avenue, Chatham Maritime, Chatham, Kent ME4 4TB, UK. ${ }^{5}$ Yaoundé Initiative Foundation, P.O. Box 3878, Messa, Yaoundé, Cameroon. ${ }^{6}$ Yaoundé Initiative Foundation, Department of Life Sciences, Faculty of Natural Sciences (Silwood Park), Imperial College London, Ascot, Berkshire SL5 7PY, UK.
\end{abstract}

Received: 8 January 2018 Accepted: 23 April 2018

Published online: 29 May 2018

\section{References}

1. Hotez PJ, Molyneux DH, Fenwick A, Kumaresan J, Sachs SE, Sachs JD, et al. Control of neglected tropical diseases. N Engl J Med. 2007;357:1018-27.
2. World Health Organization. First WHO report on neglected tropical diseases: Working to overcome the global impact of neglected tropical diseases. 2010; http://apps.who.int/iris/bitstream/10665/44440/1/9789241564090_eng. pdf. Accessed 6 Apr 2018.

3. Basáñez MG, Pion SDS, Churcher TS, Breitling LP, Little MP, Boussinesq M. River blindness: a success story under threat? PLoS Med. 2006;3:e371.

4. World Health Organization. Third WHO report on neglected tropical diseases: Investing to overcome the global impact of neglected tropical diseases. 2015; http://apps.who.int/iris/bitstream/10665/152781/1/ 9789241564861_eng.pdf. Accessed 6 Apr 2018.

5. Amazigo U, Noma M, Bump J, Benton B, Liese B, Yaméogo L, et al. Chapter 15: Onchocerciasis. In: Jamison DT, Feachem RG, Makgoba MW, Bos ER, Baingana FK, Hofman KJ, Rogo KO, editors. Disease and Mortality in SubSaharan Africa. 2nd edition. Washington (DC): The International Bank for Reconstruction and Development/The World Bank; 2006. https://www.ncbi. nlm.nih.gov/books/NBK2287/. Accessed 6 Apr 2018.

6. Coffeng LE, Stolk WA, Zouré HGM, Veerman JL, Agblewonu KB, Murdoch ME, et al. African Programme for Onchocerciasis Control 1995-2015: modelestimated health impact and cost. PLoS Negl Trop Dis. 2013;7:e2032.

7. Coffeng LE, Stolk WA, Hoerauf A, Habbema D, Bakker R, Hopkins AD, et al. Elimination of African onchocerciasis: modeling the impact of increasing the frequency of ivermectin mass treatment. PLoS One. 2014;9:e115886.

8. Benton B. Economic impact of onchocerciasis control through the African Programme for Onchocerciasis Control: an overview. Ann Trop Med Parasitol. 1998;92(Suppl.1):S33-9.

9. Molyneux DH. "Neglected" diseases but unrecognized successes - challenges and opportunities for infectious disease control. Lancet. 2004;364:380-3.

10. Amazigo U, Boatin B. The future of onchocerciasis control in Africa. Lancet. 2006;368:1946-7.

11. World Health Organization. Accelerating work to overcome the global impact of neglected tropical diseases: A roadmap for implementation. 2012; http://www.who.int/neglected_diseases/NTD_RoadMap_2012_Fullversion.pdf. Accessed 6 Apr 2018.

12. African Programme for Onchocerciasis Control. Eighteenth session of the Joint Action Forum. Bujumbura, Burundi; 2012. p. 11-3. http://www.who.int/ apoc/about/structure/jaf/Final_Communique_JAF_18_English_final_with_ annexes.pdf?ua $=1$. Accessed 6 Apr 2018

13. World Health Organization. Strategic options and alternative treatment strategies for accelerating onchocerciasis elimination in Africa. WHO/MG/15/ 20. Geneva, Switzerland: World Health Organization; 2015. http://www.who. int/apoc/ATS_Report_2015.12.pdf. Accessed 6 Apr 2018

14. Winnen M, Plaisier AP, Alley ES, Nagelkerke NJD, van Oortmarssen G, Boatin $B A$, et al. Can ivermectin mass treatments eliminate onchocerciasis in Africa? Bull World Health Organ. 2002;80:384-91.

15. Turner HC, Walker M, Churcher TS, Osei-Atweneboana MY, Biritwum NK, Hopkins A, et al. Reaching the London Declaration on Neglected Tropical Diseases goals for onchocerciasis: an economic evaluation of increasing the frequency of ivermectin treatment in Africa. Clin Infect Dis. 2014;59:923-32.

16. Awadzi K, Boakye DA, Edwards G, Opoku NO, Attah SK, Osei-Atweneboana MY, et al. An investigation of persistent microfilaridermias despite multiple treatments with ivermectin, in two onchocerciasis-endemic foci in Ghana. Ann Trop Med Parasitol. 2004;98:231-49.

17. Frempong KK, Walker M, Cheke RA, Tettevi EJ, Gyan ET, Owusu EO, et al. Does increasing treatment frequency address sub-optimal responses to ivermectin for the control and elimination of river blindness? Clin Infect Dis. 2016;62:1338-47.

18. Chippaux JP, Boussinesq M, Gardon J, Gardon-Wendel N, Ernould JC. Severe adverse reaction risks during mass treatment with ivermectin in loiasisendemic areas. Parasitol Today. 1996;12:448-50.

19. Gardon J, Gardon-Wendel N, Demanga-Ngangue, Kamgno J, Chippaux JP, Boussinesq M. Serious reactions after mass treatment of onchocerciasis with ivermectin in an area endemic for Loa loa infection. Lancet. 1997;350:18-22.

20. Kamgno J, Pion SDS, Chesnais CB, Bakalar MH, D'Ambrosio MV, Mackenzie $C D$, et al. A test-and-not-treat strategy for onchocerciasis in Loa loaendemic areas. N Engl J Med. 2017;377:2044-52.

21. Lakwo T, Garms R, Wamani J, Tukahebwa EM, Byamukama E, Onapa AW, et al. Interruption of the transmission of Onchocerca volvulus in the Kashoya-Kitomi focus, western Uganda by long-term ivermectin treatment and elimination of the vector Simulium neavei by larviciding. Acta Trop. 2017;167:128-36.

22. Basáñez MG, Walker M, Turner HC, Coffeng LE, de Vlas SJ, Stolk WA. River blindness: mathematical models for control and elimination. Adv Parasitol. 2016;94:247-341. 
23. Cheke RA, Basáñez MG, Perry M, White MT, Garms R, Obuobie E, et al. Potential effects of warmer worms and vectors on onchocerciasis transmission in West Africa. Philos Trans R Soc Lond Ser B Biol Sci. 2015;370:20130559.

24. Alley ES, Plaisier AP, Boatin BA, Dadzie KY, Remme J, Zerbo G, et al. The impact of five years of annual ivermectin treatment on skin microfilarial loads in the onchocerciasis focus of Asubende, Ghana. Trans R Soc Trop Med Hyg. 1994;88:581-4

25. Garms R, Walsh JF, Davies JB. Studies on the reinvasion of the Onchocerciasis Control Programme in the Volta River Basin by Simulium damnosum s.l. with emphasis on the south-western areas. Tropenmed Parasitol. 1979;30:345-62.

26. Matthews GA, Dobson HM, Nkot PB, Wiles TL, Birchmore M. Preliminary examination of integrated vector management in a tropical rainforest area of Cameroon. Trans R Soc Trop Med Hyg. 2009;103:1098-104.

27. Traore-Lamizana M, Somiari S, Mafuyai HB, Vajime CG, Post RJ. Sex chromosome variation and cytotaxonomy of the onchocerciasis vector Simulium squamosum in Cameroon and Nigeria. Med Vet Entomol. 2001;15:219-23.

28. Bellec C, Hebrard G. Captures d'adultes de Simuliidae, en particulier de Simulium damnosum Theobald 1903, a l'aide de pieges d'interception: les pieges vitres. Cah ORSTOM, Sér Ent Méd Parasitol. 1977;15:41-54. http//horizon.documentation.ird. fr/exl-doc/pleins_textes/divers11-12/19972.pdf. Accessed 6 Apr 2018

29. Cheke RA, Meyer RRF, Barro T, Mas J, Sima AN, Abaga SE, et al. Towards the elimination of the Bioko form of Simulium yahense from Bioko: planning and insecticide trials. Acta Zool Lituan. 2009;19:132-41.

30. Post RJ, Flook PK, Millest AL, Cheke RA, McCall PJ, Wilson MD, et al. Cytotaxonomy, morphology and molecular systematics of the Bioko form of Simulium yahense (Diptera: Simuliidae). Bull Entomol Res. 2003;93:145-57.

31. Traoré S, Wilson MD, Sima A, Barro T, Diallo A, Aké A, et al. The elimination of the onchocerciasis vector from the island of Bioko as a result of larviciding by the WHO African Programme for Onchocerciasis Control. Acta Trop. 2009;111:211-8.

32. Beaumont MA, Zhang W, Balding DJ. Approximate Bayesian computation in population genetics. Genetics. 2002;162:2025-35.

33. Cheke RA, Garms R. Reinfestations of the southeasterrn flank of the Onchocerciasis Control Programme area by windborne vectors. Philos Trans R Soc B Biol Sci. 1983;302:471-84.

34. Baker RHA, Guillet $P$, Sékétéli $A$, Poudiougo $P$, Boakye $D$, Wilson MD, et al. Progress in controlling the reinvasion of windborne vectors into the western area of the Onchocerciasis Control Programme in West Africa. Philos Trans R Soc B Biol Sci. 1990;328:731-50.

35. Grenier $P$, Féraud L. Etude biométrique et morphologique de la croissance larvaire chez Simulium damnosum Theobald. Bull Soc Pathol Exot. 1960;53: 563-81.

36. Christiansen-Jucht C, Erguler K, Shek CY, Basáñez MG, Parham PE. Modelling Anopheles gambiae s.s. population dynamics with temperature- and agedependent survival. Int J Environ Res Public Health. 2015;12:5975-6005.

37. Baker RHA, Abdelnur OM. Localized onchocerciasis vector control in the Bahr el Ghazal Region of South-Western Sudan. II. Control. Trop Med Parasitol. 1986;37:135-42

38. Davies JB. Sixty years of onchocerciasis vector control: a chronological summary with comments on eradication, reinvasion, and insecticide resistance. Annu Rev Entomol. 1994;39:23-45.

39. Kalinga AK, Mweya CN, Barro T, Maegga BTA. Susceptibility of Simulium damnosum complex larvae to temephos in the Tukuyu onchocerciasis focus, southwest Tanzania. Tanzan Health Res Bull. 2007;9:19-24.

40. Csilléry K, François O, Blum MGB. Abc: An R package for approximate Bayesian computation (ABC). Methods Ecol Evol. 2012;3:475-9.

41. Blum MGB, François O. Non-linear regression models for Approximate Bayesian Computation. Stat Comput. 2010;20:63-73.

42. Wanji S, Kengne-Ouafo JA, Esum ME, Chounna PWN, Tendongfor N, Adzemye BF, et al. Situation analysis of parasitological and entomological indices of onchocerciasis transmission in three drainage basins of the rain forest of South West Cameroon after a decade of ivermectin treatment. Parasit Vectors. 2015:8:202.

43. Verver S, Walker M, Kim YE, Fobi G, Tekle A, Zouré H, et al. How can onchocerciasis elimination in Africa be accelerated? Modelling the impact of increased frequency of ivermectin distribution and complementary vector control. Clin Infect Dis. 2018; in press

44. Dietz K. The population dynamics of onchocerciasis. In: Anderson RM, editor. Population dynamics of infectious diseases. London: Chapman \& Hall; 1982. p. 209-41.
45. Basáñez MG, Boussinesq M. Population biology of human onchocerciasis. Philos Trans R Soc Lond Ser B Biol Sci. 1999;354:809-26.

46. Basáñez MG, Collins RC, Porter CH, Little MP, Brandling-Bennett D. Transmission intensity and the patterns of Onchocerca volvulus infection in human communities. Am J Trop Med Hyg. 2002;67:669-79.

47. Duerr HP, Eichner M. Epidemiology and control of onchocerciasis: the threshold biting rate of savannah onchocerciasis in Africa. Int J Parasitol. 2010;40:641-50.

48. Basáñez MG, Churcher TS, Grillet ME. Onchocerca-Simulium interactions and the population and evolutionary biology of Onchocerca volvulus. Adv Parasitol. 2009:68:263-313.

49. Lamberton PHL, Cheke RA, Walker M, Winskill P, Crainey JL, Boakye DA, et al Onchocerciasis transmission in Ghana: the human blood index of sibling species of the Simulium damnosum complex. Parasit Vectors. 2016;9:432.

50. Hougard JM, Escaffre H, Darriet F, Lochouarn L, Rivière F, Back C. An episode of resistance to permethrin in larvae of Simulium squamosum (Diptera: Simuliidae) from Cameroon, after 3 and 1/2 years of control. J Am Mosq Control Assoc. 1971;8:184-6.

51. Kurtak DC. Insecticide resistance in the Onchocerciasis Control Programme. Parasitol Today. 1986;2:20-1.

52. Hougard JM, Poudiougo P, Guillet P, Back C, Akpoboua LK, Quillévéré D. Criteria for the selection of larvicides by the Onchocerciasis Control Programme in west Africa. Ann Trop Med Parasitol. 1993;87:435-42.

53. World Health Organization. Guidelines for laboratory and field testing of mosquito larvicides. WHO/CDS/WHOPES/GCDPP/2005.13. Geneva: WHO; 2005. p. 39. http://whqlibdoc.who.int/hq/2005/WHO_CDS_WHOPES_ GCDPP_2005.13.pdf. Accessed 4 Apr 2018

54. Davies JB, Crosskey RW, World Health Organization. Simulium - vectors of onchocerciasis. Advanced level training and information guide. Division of Control of Tropical Diseases. WHO/NBC/91.992. Geneva: World Health Organization; 1991. p. 115. http://apps.who.int/iris/bitstream/handle/10665/ 59007/WHO_VBC_91.992.pdf. Accessed 4 Apr 2018.

55. Davies JB. Description of a computer model of forest onchocerciasis transmission and its application to field scenarios of vector control and chemotherapy. Ann Trop Med Parasitol. 1993;87:41-63.

56. Turner HC, Walker M, Attah SK, Opoku NO, Awadzi K, Kuesel AC, Basáñez MG. The potential impact of moxidectin on onchocerciasis elimination in Africa: an economic evaluation based on the Phase II clinical trial data. Parasit Vectors. 2015;8:167.

57. Churcher TS, Kaplan RM, Ardelli BF, Schwenkenbecher JM, Basáñez MG, Lammie PJ. Mass treatment of parasitic disease: implications for the development and spread of anthelmintic resistance. In: Weber JT, editor. Antimicrobial Resistance - Beyond the Breakpoint, vol. 6. Basel: Karger. Issues Infect Dis; 2010. p. 1-18.

58. Post RJ, Cheke RA, Boakye DA, Wilson MD, Osei-Atweneboana MY, TettehKumah A, et al. Stability and change in the distribution of cytospecies of the Simulium damnosum complex (Diptera: Simuliidae) in southern Ghana from 1971 to 2011. Parasit Vectors. 2013:6:205.

59. Lamberton PHL, Cheke RA, Walker M, Winskill P, Osei-Atweneboana MY, Tirados I, et al. Onchocerciasis transmission in Ghana: biting and parous rates of host-seeking sibling species of the Simulium damnosum complex. Parasit Vectors. 2014;7:511.

60. Post RJ, Onyenwe E, Somiari SAE, Mafuyai HB, Crainey JL, Ubachukwu POA. guide to the Simulium damnosum complex (Diptera: Simuliidae) in Nigeria, with a cytotaxonomic key for the identification of the sibling species. Ann Trop Med Parasitol. 2011;105:277-97.

61. Davies JB, Sékétéli A, Walsh JF, Barro T, Sawadogo R. Studies on biting Simulium damnosum s.l. at a breeding site in the Onchocerciasis Control Programme area during and after an interruption of insecticidal treatments. Tropenmed Parasitol. 1981;32:17-24.

62. Edwards AJ, Trenholme AAG. Diel periodicity in the adult eclosion of the blackfly, Simulium damnosum Theobald, in the Ivory Coast. Ecol Entomol. 1976;1:279-82.

63. Cheke RA, Garms R, Kerner M. The fecundity of Simulium damnosum s.l. in northern Togo and infections with Onchocerca spp. Ann Trop Med Parasitol. 1982:76:561-8. 